\title{
Individual's perceivable range and the notion of unexpectedness
}

\author{
Minh-Hoang Nguyen \\ Centre for Interdisciplinary Social Research \\ Phenikaa University \\ Yen Nghia, Ha Dong, Hanoi 100803, Vietnam
}

January 17, 2022

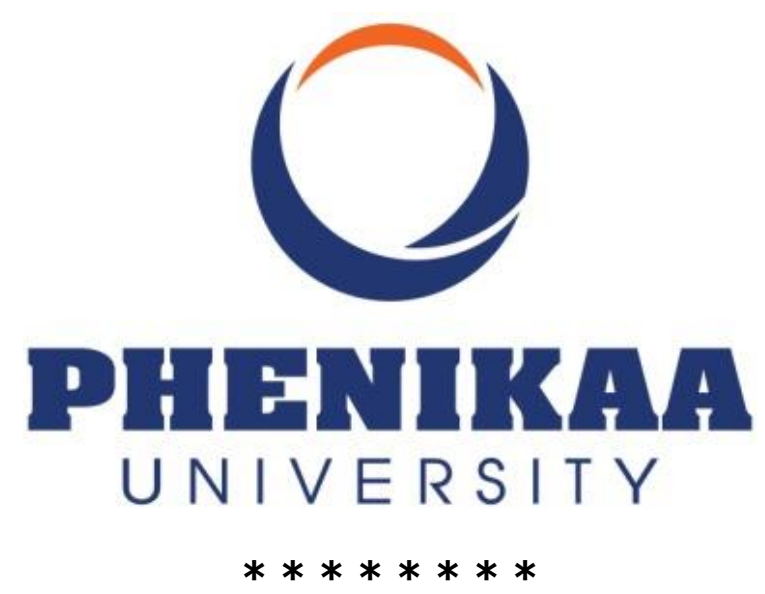

When conducting research on serendipity, I could see many researchers emphasize the notion of unexpectedness in the context of serendipity (André et al., 2009; Copeland, 2019; Cunha, 2005; Cunha et al., 2010; De Rond, 2014; Lawley \& Tompkins, 2011; Makri \& Blandford, 2012; McCay-Peet \& Toms, 2010; McCay-Peet \& Toms, 2015; Mendonça et al., 2008; Merton \& Barber, 2004; Napier \& Vuong, 2013; Rubin et al., 2011; Vuong, 2022). According to the Oxford dictionary, unexpectedness is the fact that something surprises you because you were not expecting it. Based on the information processing mechanisms (Levy et al., 2007; Nguyen, 2021; Vuong, 2016; Vuong et al., 2022; Vuong \& Napier, 2015; Vuong \& Napier, 2014), I think that unexpectedness is a person's subjective perceptions of a certain event but not entirely the objective existence of the event itself. Former works on serendipity models and processes also shared analogous viewpoints. For example, Lawley and Tompkins (2011) suggest that the serendipity process is a perceptual process that comprises six major components, including the unexpected event. Meanwhile, McCay-Peet and Toms (2015)'s model mentions the perception of serendipity as one out of six major elements of the serendipity process. They refer to the perception of serendipity as an experience "understood or regarded to be serendipitous based on awareness of its trigger, connection, valuable outcome, and unexpected thread." 
The unexpected moment happens when a person subjectively expects it not to happen as it does or when a person first perceives novel information to which they have no reference in mind. Therefore, there can be two circumstances (Nguyen, 2022).

- Unexpectedness from within the perceivable range: In the first circumstance, the thing/event that surprises a person has already been existing or occurred within the perceivable range of that person for a certain period, but that person does not notice or perceive its existence/occurrence. For some reason, the person becomes aware of that thing/event and considers it to be unexpected. By saying perceivable range, we mean the physical range (or environment) within which a person can see, hear, or become aware of something through the senses. For instance, on the way from home to school or office, the surrounding scenes, sounds, and smells are things/events that can be perceived; After a long walk, the person feels surprised when he/she recognizes that the person walking alongside for a while is their friend. Another example is that many people may listen to both Twinkle Twinkle Little Star and The ABC songs, but they may not recognize immediately that they have the same tune. One may consider doing science as costly, but not until they can completely understand the values humans have been receiving from science (Vuong, 2018).

- Unexpectedness from beyond the perceivable range: In the second circumstance, the thing/event that surprises a person does not exist or occur within the past or current perceivable range of that person but comes from outside of the perceivable range. A person may not intentionally seek that information, but due to the changes in the environment, a thing/event suddenly appears or occurs within the person's perceivable range and makes them surprised. For instance, on the way from home or to school or office, one unexpectedly runs into their friend who just walks out of a nearby restaurant.

These two circumstances are derived from two fundamental assumptions about human physical and mental capacities. The first assumption is that a person's mental capacity has a certain limit, so they cannot perceive, evaluate, and absorb all the information from their perceivable range. For example, a person cannot see all the details in a complex illustration but can solely focus on a specific part of the illustration at a time; Where's Wally - a British animated series of children's puzzle books created by an English illustrator Martin Handford - is a prime example. The second assumption is that a person's physical capacity has a certain limit, so they cannot receive information from out of their perceivable range. For example, one cannot see things/events that exist or occur without their eyesight; a person cannot directly see the Eiffel Tower in France while standing in front of the Washington Monument in the United States. 


\section{References}

André, P., Schraefel, M., Teevan, J., \& Dumais, S. T. (2009). Discovery is never by chance: designing for (un) serendipity. Proceedings of the seventh ACM conference on Creativity and cognition.

Copeland, S. (2019). On serendipity in science: discovery at the intersection of chance and wisdom. Synthese, 196(6), 2385-2406.

Cunha, M. P. (2005). Serendipity: Why some organizations are luckier than others. FEUNL Working Paper Series, 472.

Cunha, M. P. E., Clegg, S. R., \& Mendonça, S. (2010). On serendipity and organizing. European Management Journal, 28(5), 319-330.

De Rond, M. (2014). The structure of serendipity. Culture and Organization, 20(5), 342358.

Lawley, J., \& Tompkins, P. (2011). Maximising serendipity: The art of recognising and fostering unexpected potential - A systemic approach to change. The Clean Collection. Retrieved December 31 from https://cleanlanguage.co.uk/articles/articles/224/1/MaximisingSerendipity/Page1.html

Levy, O., Beechler, S., Taylor, S., \& Boyacigiller, N. A. (2007). What we talk about when we talk about 'global mindset': Managerial cognition in multinational corporations. Journal of International Business Studies, 38(2), 231-258.

Makri, S., \& Blandford, A. (2012). Coming across information serendipitously-Part 1: A process model. Journal of Documentation, 68(5), 684-705.

McCay-Peet, L., \& Toms, E. G. (2010). The process of serendipity in knowledge work. Proceedings of the third symposium on Information interaction in context,

McCay-Peet, L., \& Toms, E. G. (2015). Investigating serendipity: How it unfolds and what may influence it. Journal of the Association for Information Science and Technology, 66(7), 1463-1476.

Mendonça, S., Cunha, M., \& Clegg, S. R. (2008). Unsought innovation: serendipity in organizations. Entrepreneurship and Innovation-Organizations, Institutions, Systems and Regions Conference, Copenhagen.

Merton, R. K., \& Barber, E. (2004). The Travels and Adventures of Serendipity : A Study in Sociological Semantics and the Sociology of Science. Princeton University Press.

Napier, N., \& Vuong, Q. H. (2013). Serendipity as a Strategic Advantage? In T. Wilkinson (Ed.), Strategic Management in the 21st Century (pp. 175-199). Praeger/ABC-Clio.

Nguyen, M.-H. (2022). Conditions for improving serendipity encounter and attainment probability. In: QH Vuong. (Ed.) A New Theory of Serendipity: Nature, Emergence and Mechanism (pp. 109-130). Berlin, Germany: De Gruyter.

Nguyen, M.-H. (2021). Subjective spheres of influence: A perceptual system beyond Mindsponge. PhilArchive. Available at: https://philarchive.org/rec/NGUSSO

Rubin, V. L., Burkell, J., \& Quan-Haase, A. (2011). Facets of serendipity in everyday chance encounters: a grounded theory approach to blog analysis. Information Research, 16(3), 488. 
Vuong, Q.-H. (2016). Global Mindset as the Integration of Emerging Socio-Cultural Values Through Mindsponge Processes: A Transition Economy Perspective. In J. Kuada (Ed.), Global Mindsets: Exploration and Perspectives (pp. 109-126). Routledge.

Vuong, Q.-H. (2018). The (ir)rational consideration of the cost of science in transition economies. Nature Human Behaviour, 2, 5.

Vuong, Q.-H., Le, T.-T., La, V.-P., Nguyen, T. T. H., Ho, M.-T., Khuc, Q., \& Nguyen, M.$H$. (2022). Covid-19 vaccines production and societal immunization under the serendipity-mindsponge-3D knowledge management theory and conceptual framework. Humanities and Social Sciences Communications, 9, forthcoming.

Vuong, Q.-H., \& Napier, N. K. (2015). Acculturation and global mindsponge: an emerging market perspective. International Journal of Intercultural Relations, 49, 354-367.

Vuong Q.-H.. (2022). A New Theory of Serendipity: Nature, Emergence and Mechanism. Berlin, Germany: De Gruyter.

Vuong, Q. H., \& Napier, N. K. (2014). Making creativity: the value of multiple filters in the innovation process. International Journal of Transitions and Innovation Systems, 3(4), 294-327. 